\title{
Commentary on "Nondualistic Experiences of Light in Near-Death Experiences and in The Tibetan Book of the Dead"
}

\author{
Todd Murphy \\ www.spiritualbrain.com
}

\begin{abstract}
René Jorgensen's editorial comparing the Clear Light in The Tibetan Book of the Dead (or Bardo Thodol) and the experience of light in some near-death experiences (NDEs) does not adequately acknowledge either the diversity of NDEs or the possibility that the content of The Tibetan Book of the Dead may be metaphorical. Similarities between descriptions of light in some NDEs and descriptions of the Clear Light in The Tibetan Book of the Dead may reflect similar underlying neural mechanisms and does not provide validation for either description. Any relevance of these descriptions to enlightenment is speculative.
\end{abstract}

KEY WORDS: near-death experience; The Tibetan Book of the Dead; light; Clear Light; enlightenment; liberation.

This commentary in is response to René Jorgensen's guest editorial, "Nondualistic Experiences of Light in Near-Death Experiences and in The Tibetan Book of the Dead." In the abstract, Jorgensen wrote that he would compare the Clear Light in The Tibetan Book of the Dead (or Bardo Thodol) and in near-death experiences (NDEs), and that this comparison will give an answer to the question whether the NDE is similar to the Clear light of the Ground Luminosity.

Todd Murphy is a Researching Behavioral Neuroscientist and an associate member of Laurentian University's Neuroscience Research Group. He is also the webmaster at www.spiritualbrain.com, a nontechnical website about spirituality and the brain. Reprint requests should be addressed to Mr. Murphy at 360 Hyde Street, \#407, San Francisco, CA 94109; e-mail: brainsci@jps.net. 
While discussion on this point is certainly within the scope of the Journal of Near-Death Studies, the specific approach taken here is weakened by Jorgensen's emphasis on his own near-death experience, and not enough consideration of excerpts from other firsthand accounts of NDEs. Although he does quote many published accounts, Jorgensen draws his conclusions by placing too much reliance on the convergence between his own experiences and Tibetan Buddhist teachings. A better frame of reference would be "typical" NDEs, as they appear in several cultures. For example, in Thailand, a Buddhist country where the Bardo Thodol is almost unknown, most NDEs feature messengers from the underworld and do not make references to "The Light," although it does appear frequently in occidental NDEs and in The Tibetan Book of the Dead. Comparisons of NDEs to the "Grand Luminosity" will uncover similarities, but they will probably be culture-specific ones. There are too many accounts of NDEs, especially "hellish" experiences, that bear no similarities to Bardo Thodol episodes for it to be taken as a model for the workings of NDEs.

Although phenomena described in The Tibetan Book of the Dead can indeed be found in many NDE accounts, it must be born in mind that The Tibetan Book of the Dead is a scripture, one authored by a single known individual, Padmasambhava. Because it is presumed that the book is not based on firsthand accounts of postmortem experiences, it has no compelling relevance to subjective experience occurring following clinical death. As such, it offers no evidence in the usual sense of the word. Rather, it can only inspire speculation. The possibility remains that The Tibetan Book of the Dead is a metaphorical document, and that similarities in the "Light experience" described in both sources is coincidence. There is also the possibility that these experiences are composed of the meditation experiences of the Padmasambhava, who equated them with postmortem experiences. Still another possibility is that it is a "channeled" text, not unlike the Book of Mormon or the Quran, and has no more claim to truth than any other individual scripture.

There is no evidence that bardos even exist; or rather there is as much evidence for the existence of bardos as there is for heaven and hell. Even though there are hellish near-death experiences, and these experiences may provide the basis for a meme consisting of belief in eternal constant torture, that does not mean that hell, as understood in Christian tradition, is a common experience after death. Christian 
belief in the Day of Judgment may reflect a life review, but that does not mean that life reviews function to pass judgment. I am not saying that the bardos do not exist, but only that an argument for their existence is called for, and that Jorgensen's paper does not make one.

There are many contexts in which light is discussed in Buddhism, and The Tibetan Book of the Dead is only one. Jorgensen does indeed make reference to Dharmakaya, which is the name given for the experience of Clear Light when it occurs during meditation, as well as for the state of consciousness in which it happens. I am quite willing to accept that this is the same as the Clear Light that occurs in neardeath experiences. I accept this not only because the descriptions match, but more because it seems probable that the underlying neural mechanisms are the same, a suggestion that gains credence from the observation that "The Light" has been reported from many other contexts, including meditation, hyperventilation, twilight sleep states, and others.

The purpose of The Tibetan Book of the Dead is to help people achieve enlightenment after they have died. Jorgensen implies that people are not liberated in the course of NDEs because they either "fail to recognize the Clear Light, or because they are not able to remain in its continuity." Perhaps enlightenment is possible during near-death experiences, but if so, introducing the subject into the peer-reviewed literature should entail a reasonable definition for the term "enlightenment," as well as an argument, based on secular evidence, in favor of its existence. Here, Jorgensen simply assumes that there is such thing as enlightenment, expects his reader to agree, and introduces questions that will make little sense for anyone who does not share the author's religious orientation.

Jorgensen wrote that he saw similarities between his own experiences and the contents of The Tibetan Book of the Dead, and appears to have accepted that the purpose of the bardos is to facilitate enlightenment, and then imposes then same idea on near-death experiences. An alternative may be that the "purpose" of NDEs is to contribute somehow to our survival as a species. The suggested role for enlightenment in his hypothesis makes it distinctly teleological.

In addition, the author assumes the existence of an "ultimate reality." While there might be something for which that label is appropriate, its existence should be demonstrated, or it should be explicitly labeled as an assumption or a postulate. 
Jorgensen's primary theme, that of comparing descriptions of the Clear Light in The Tibetan Book of the Dead with descriptions of "the Light" in NDEs, is a good and valid theme. However, his paper was concerned with other issues, requiring references to nonduality, ultimate reality, liberation, and other categories. Although these are well established in Buddhism, they have yet to be demonstrated in any meaningful way for the near-death research community.

Using religious ideas as postulates, as is done here, blurs the distinction between scientific method (the source for scientific ideas) and faith, visions, scriptures, and the other sources for religious ideas. I believe that these distinctions should be maintained, and that losing these distinctions poses a greater risk to near-death studies than to any other field in the sciences, precisely because near-death experiences are so very close to the "heart" of religions. Indeed, all popular religions have teachers who say that the religious life is one that prepares one for death. The study of the experiences that actually occur at death has far-reaching implications for the world's traditional religions, though these implications may differ from one religion to the next. 